\title{
Design of Die and Parameters for Grain Refinement of AA5XXX Series Through Equal Channel Angular Pressing: An Overview
}

\author{
Nagendra Singh ${ }^{1 *}$, Dr. Manoj Kumar Agrawal' ${ }^{2}$,Sanjeev Kumar Verma ${ }^{3}$ \\ ${ }^{1}$ Research Scholar Dept. of Mechanical Engineering. G.L.A .University, Mathura, INDIA \\ ${ }^{2}$ Dept. of Mechanical Engineering. G.L.A .University, Mathura, INDIA \\ ${ }^{3}$ Dept. of Mechanical Engineering. J.S .University, Shikohabad, INDIA \\ *Corresponding author
}

\begin{abstract}
A material with low weight and great strength is a basic requirement of industry. There are a variety of approaches for improving mechanical characteristics and microstructure, but most successful demonstrate of ECAP method. One of the most well-known grain refining procedures for extreme plastic deformation is Equal Channel Angular Pressing (ECAP). The die plays a vital role in this procedure. Friction, Corner angle, the total number of passes, channel angle, routes, back pressure, and other variables can all influence the process's outcome. By Equal Channel Angular Pressing process variables that influence the mechanical equities of the AA5XXX series have been studied and analysed in this study for a better conclusion. Materials that have passed the ECAP test have improved mechanical, physical properties and micro structural Properties. The main alloying element for the 5000 series are Mg, AA5XXX alloys and their enhanced mechanical properties have become crucial criteria for their use for architectural and automotive trim, petrol tanks, high strength foil, dump track bodies, pressure cryogenic vessels, fittings and marine structures, components. Magnesium is the main element in the 5000 series alloys, and it is one of the most effective and extensively utilized alloying elements for aluminium. These are non-heat-treatable, moderate-to-high-strength alloys that are easily weldable and have excellent corrosion resistance, even in maritime applications.
\end{abstract}

Keywords: Corner angle, Plastic deformation homogeneity, Die Design, Equal Channel angular pressing, Fabrication, Types of Routes, Severe Plastic Deformation.

\section{INTRODUCTION:}

Severe plastic deformation is a technique for improving material characteristics by reducing grain size, which leads to microstructure refinement and, in turn, increased mechanical performance. Roll bonding accumulative, ECAP, multi axial forging, high pressure, and other techniques are used in SPD. Among these, ECAP is the most effective method for improving mechanical properties. The physical and mechanical qualities of a matter can be defined by its regular grain size. The expression between grain size $\mathrm{d}$ and yield stress is represented in equation. It represented by relationship shown in equation I. Assume $\mathrm{k}$ is the yield constant and $\sigma_{0}$ is the friction stress. [1,2].

$$
\sigma_{y}=\sigma_{0}+k d^{\frac{-1}{2}}
$$

The ECAP method, in which the sample is pushed to foist high stress at junction, necessitates the use of a die with two intersecting channels. Two key factors (corner angle and channel angle, sequentially) influence the charge in strain and, as a result, the process's end result. Figure 1 [3] shows a schematic diagram of ECAP. ECAP is a process that is defined as being homogeneous. The term "homogeneity" refers to a homogeneous stress distribution in the workpiece, however it is affected by a number of elements. In ECAP, die design is very critical. The outcomes of dying can be influenced by both internal and external circumstances. Die shape, temperature, friction, loading charge, speed of ram, back pressure, and passage paths are all external influences. Internal variables are largely determined by the workpiece's material and qualities. This article investigates the many elements that influence homogeneity. For mechanical properties, an experimental investigation was conducted to determine the real percentage augmentation in attributes for the AA5083 aluminium pieces [4-7]. The first use of aluminium was in 1894, when Hart-ford Railroads produced aluminium frame for the seat for a bright load car. Later applications included automotive trim, architectural components, dump track bodies, pressure cryogenic vessels, naval constructions and fittings, gasoline tanks, and high-strength foil. The major reasons for its employment are its light weight, high strength, and corrosion resistance. The advantages were extremely beneficial to the industry. Aluminum's use in all fields rose as a result of this. Different aluminium alloys are treated under 


\section{International Advanced Research Journal in Science, Engineering and Technology \\ Impact Factor $7.105 \div$ Vol. 9, Issue 1, January 2022 \\ DOI: 10.17148/IARJSET.2022.9141}

ECAP for diverse applications as a result of extensive research on ECAP and its uses. The AA5083 from 5000 series is one of the most widely used aluminium series, and ECAP processes it extensively. Magnesium is the primary alloying element in this series. This family of alloys has a moderate strength. Heat treatment results in great machinability due to the magnesium-aluminum alloy [AA5083]. It's commonly utilised in welding, electrical hardware, and a variety of other applications [7].

\section{LITERATURE REVIEW:}

In article Djavanroodi [9], explore the back pressure, , coefficient of friction and accomplish on channel angleon strain development when a illustration is passed through ECAPed. Using FEM analysis, he discovered that decreasing the channel angle increases the strain in the sample, resulting in higher homogeneity and microstructure refinement. A minor channel angle and a towering coefficient of friction remove the gap at the corner that is discovered by the sample, allowing for higher strains. Both of these things will raise the required press pressure. If the channel angle is reduced from $120^{\circ}$ to $60^{\circ}$, the pressure requirement might be increased by three times. Homogeneity will be increased as a result of back pressure, but the change will be fewer obvious. In article Ebrahimi [10] investigates the parameters that influence strain and homogeneity during ECAP processing. The channel angle and displacement were investigated. According to him, channel angle has a greater impact on the quantity of strain created in the sample. He employed a equidistant die and came to the conclusion that channel displacement has a smaller impact on the amount of strain, but it does promote uniformity. Reducing the channel angle and shortening to the displacement degree of the strain will rise as the length enlarges while also increasing the pressure required. The usage of a equidistant die can be employed to defeat the corner gap, hence increasing the efficiency of the ECAP Process. Article of Thakur [11] examines past and current advances ECAP is in the process of being designed. Apart from splite dies, spring loaded dies, rotary dies, coiled dies, and T-shaped dies are fresh advancements in die design, according to him. The fundamental benefit of a rotary die is that the material is not withdrawn from the die for a number of passes since the die has four channels bisect at 90 degrees. The revolving of the die allows for a greater number of passes without having to remove material from the die. The spring-loaded die is primarily used to reduce plunger force requirements because the spring aids in force restoration. Other techniques, alike as ultrasonic ECAP or torsional ECAP, are being used in conjunction with ECAP. During the procedure, ultrasonic energy is employed to help reduce material cracking and make the process run more smoothly. Torsion is employed ECAP at the outlet channel in torsion for additional improvement in characteristics and micro-structural. Mathieu [12] presented a novel ECAP die design. He claims that because friction is a crucial factor in the process, to reduce friction, a new modified die with movable channel was constructed. He suggested that the die material be Inconel 718 or stainless steel along some modifications, such as thermal insulation. The material used should have a high tensile strength. It consists of 2 fixed components and 1 movable component along a die channel. After passing through the stationary component, the item is placed in the shifting part. The outlet channel is a permanent feature. He discovered that by doing so, the friction in the die is reduced, and the characteristics and microstructure of the die are improved. Patricia-Pena investigates the optimal die design for ECAP in [13]. He looked into it using a FEM study with six alternative die configurations and amount of friction. He believes that several passes are advantageous, and that as the friction amount decreases, the homogeneity of the structure increases. According to the FEM analysis, die with $\Phi=120^{\circ}, \Psi=30^{\circ}$ and a friction of amount $=0.05$ are best die variables for ECAP process. Dayal [14] investigates ECAP die design by minimising the corner gap, which is a result of corner angle and friction amount. He used FEM evaluate to determine that for a round die, a corner angle greater than 30 degrees does not result in the creation of a corner gap. He concludes that tougher materials are frictionindependent, but softer materials have greater homogeneity when subjected to big friction. He also claims that a corner angle of 30 degrees and a fillet radius of $5 \mathrm{~mm}$ are optimum for a homogeneous construction with low strain attentiveness.

\section{METHOD AND MATERIAL:}

A split die with channel angle $\Phi=120^{\circ}$, and corner angle $\Psi=30^{\circ}$, is constructed in the laboratory based on literature analysis and previous studies. The die with outer dimension is $170 \times 145 \times 50 \mathrm{~mm}$. The diameter of the billet is $45 \mathrm{~mm}$, and the length of the workpiece is $114 \mathrm{~mm}$. Die plates are made of high-speed tool steel, T4/T6 $50 \mathrm{~mm}$ thick, and there are two of them. Nut-bolts: $+20 \mathrm{~mm}$ because of its great strength and suitability for both cold and hot operations, it has a composition of about 0.5 percent. Six Allen bolts and two keys connect the two sections of the split die. The keys aid in better alignment of the two parts and limit movement. Half threaded Allen bolt with double nuts and hardened washer. In this particular study Aluminium-5083 is used. 5083 aluminium alloy is an aluminium alloy with magnesium and traces of manganese and chromium. Al 5083 is the most common alloy used for Ship building, Rail Cars, Vehicle bodies, Tip Truck Bodies, Mine Skips and Cages, Pressure vessels. Molybdenum Disulfide $\left(\mathrm{MoS}_{2}\right)$ is used for lubrication during the ECAP Process. 


\title{
International Advanced Research Journal in Science, Engineering and Technology \\ Impact Factor 7.105 Vol. 9, Issue 1, January 2022 \\ DOI: 10.17148/IARJSET.2022.9141
}

Table 1. Aluminium alloy 5083 chemical composition

$\begin{array}{llllllllll}\text { Element } & \mathrm{Si} & \mathrm{Fe} & \mathrm{Cu} & \mathrm{Mn} & \mathrm{Mg} & \mathrm{Zn} & \mathrm{Ti} & \mathrm{Cr} & \mathrm{Al} \\ \text { \% Present } & 0.4 & 0.4 & 0.1 & 0.4-1.0 & 4.0-4.9 & 0.25 & 0.15 & 0.05-0.25 & \text { Balance }\end{array}$

\begin{abstract}
Aluminum Alloys:
The two forms of aluminium alloys are wrought alloys, which are manipulated to shape, and cast alloys, which are poured in a molten state into a mould that specifies their shape. Minor alloying elements like as manganese $(\mathrm{Mg}), \mathrm{chromium}(\mathrm{Cr})$, titanium (Ti), vanadium $(\mathrm{V})$, beryllium $(\mathrm{Be})$, and gallium $(\mathrm{Ga})$ can be added to the alloys of the $5 \mathrm{xxx}$ series.

The enormous range of properties of alloys explains why they are used in so many different applications, from aeronautics to packaging. Aluminum Alloys That Cannot Be Heat Treated: Non-heat treatable aluminium alloys are made of of solidstate elements and few types of particles. Heat treatment will not develop any strengthening precipitates in this alloy, unlike heat treatable alloys (the dispersions formed in Al-Mn alloys are an exception). Because solute atoms are removed after heat treatment, the strength may actually decrease. The alloy systems that belong to this class are the AA1xxx system (commercially pure with small amounts of mainly $\mathrm{Fe}$ and $\mathrm{Si}$ ), the AA3xxx system (as AA1xxx with manganese and magnesium additions), the AA5xxx system (as AA1 xxx with magnesium addition), and the AA8xxx system (as AA1xxx but with higher alloy additions). Aluminum Alloys That Can Be Heat Treated: The AA2xxx, AA6xxx, and AA7xxx alloy systems are heat-treatable aluminium alloys that obtain their strength mostly from precipitate particles. These alloys are heated to the single phase area of the phase diagram, where the alloying elements dissolve to a greater or lesser amount into solid solution.
\end{abstract}

Table 1: Wrought aluminium and its alloys [35, 36]; AA Designation

\begin{tabular}{|l|l|l|l|l|l|l|l|l|}
\hline $\begin{array}{l}\text { Alloying } \\
\text { Elements }\end{array}$ & $\begin{array}{l}\text { Pure } \\
\text { Aluminium }\end{array}$ & Copper & Manganese & Silicon & Magnesium & $\begin{array}{l}\text { Magnesium } \\
\text { and Silicon }\end{array}$ & Zinc & Lithium \\
\hline $\begin{array}{l}\text { Series } \\
\text { Designation }\end{array}$ & AA1XXX & AA2XXX & AA3XXX & AA4XXX & AA5XXX & AA6XXX & AA7XXX & AA8XXX \\
\hline
\end{tabular}

Table 2: Cast Aluminium and its alloys [35, 36]; AA Designation

\begin{tabular}{|l|l|l|l|l|l|l|l|}
\hline $\begin{array}{l}\text { Alloying } \\
\text { Elements }\end{array}$ & $\begin{array}{l}\text { Pure } \\
\text { Aluminium }\end{array}$ & Copper & $\begin{array}{l}\text { Silicon, with } \\
\text { copper and/or } \\
\text { Manganese }\end{array}$ & Silicon & Magnesium & Zinc & Lithium \\
\hline $\begin{array}{l}\text { Series } \\
\text { Designation }\end{array}$ & AA1XXX & AA2XXX & AA3XXX & AA4XXX & AA5XXX & AA7XXX & AA8XXX \\
\hline
\end{tabular}

\section{Equal Channel Angular Pressing:}

Segal [5] was the first to present Equal Channel Angular Pressing (ECAP) at the Minsk Institute in the Soviet Union. A plunger is utilised to provide pressure to the material in this procedure. It is made up of two specific channels that meet at an oblique angle known as the channel angle $\varnothing$ on a special die. Material grain size is one of the most important parameters influencing the mechanical behaviour of base metals and alloys in all SPD techniques, such as ECAP, High Pressure Torsion (HPT), Accumulative Roll Bonding (ARB), Constrained Groove Pressing (CGP), Accumulative Back Extrusion (ABE), Tubular Channel Angular Pressing (TCAP), and so on. During ECAP, a piece is squeezed through two intersecting channels with the same cross-sections and a die channel angle $\varnothing$ of and an outer corner angle of with a die channel angle of and an outer corner angle of $\varphi$. Because of the accumulative shear strain at each pass, billets with a high value of plastic strain can be formed during this procedure. In the frictionless state, the magnitude of shear strain after one pass ECAP is determined with [37]:

$$
\gamma=2 \cot \left(\frac{\emptyset+\varphi}{2}\right)+\varphi \operatorname{cosec}\left(\frac{\emptyset+\varphi}{2}\right)
$$

The corner angle $\varphi$ is the angle formed by the cross section of the two channels at their convergence. Strain tends to form in the material at the place where the two channels meet [8].

$$
\epsilon_{N}=\frac{N}{\sqrt{3}}\left[2 \cot \left(\frac{\emptyset}{2}+\frac{\varphi}{2}\right)+\varphi \operatorname{cosec}\left(\frac{\emptyset}{2}+\frac{\varphi}{2}\right)\right]
$$

Equation II shows the relationship between produced strain and external influences.

The ECAP principle is illustrated in Figure 1 by a die with a bent internal channel angle and a corner angle that depicts the outside arc of curvature and two intersecting channels. A billet is machined or a load is applied to pass the channel in a die. In the die, billets are pressed with a plunger into the die's channel (a full study of these angles has been mentioned above). In this test, we tried to determine the best feasible settings that would give us the best outcome in terms of strain homogeneity. The sample via die is passed repeatedly to achieve the extraordinarily high strain because the cross sectional 


\section{International Advanced Research Journal in Science, Engineering and Technology \\ Impact Factor 7.105 ㄷ Vol. 9, Issue 1, January 2022 \\ DOI: 10.17148/IARJSET.2022.9141}

area remains unaltered. To acquire the best results, this test is run for $\mathrm{U}$ from $90^{\circ}$ to $120^{\circ}$, W equal to $0^{\circ}$, and an increment of $15^{0}$ for both angles.
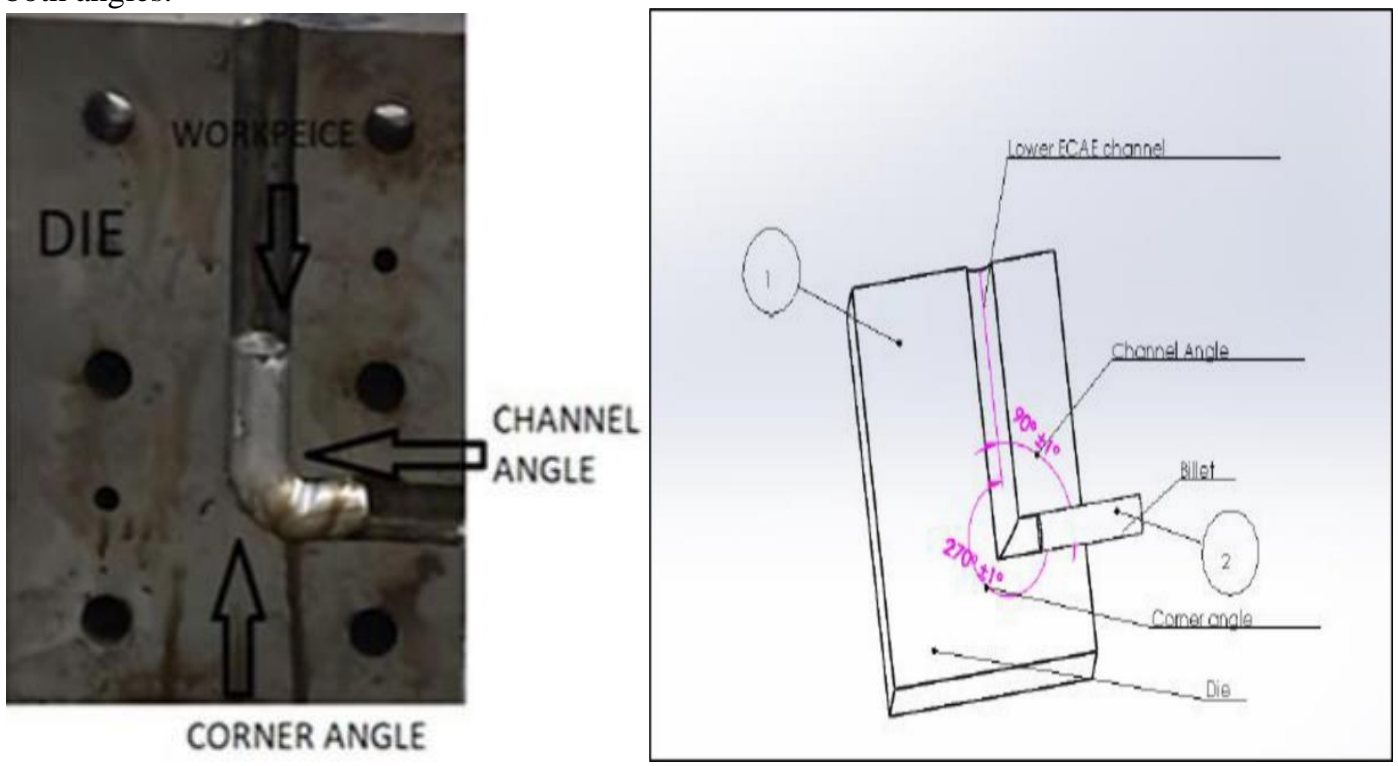

Figure 1 Schematic diagram of ECAP process showing die, corner angle, billet, channel angle, .

To achieve better refinement, the sample is repeatedly cycled through the path of the die [4-7]. The number of passes is $\mathrm{N}$ in this case. In Figure 2, This procedure can be carried out in one of four ways. Figure 2 is describing all four routes, Route $\mathrm{A}\left[0^{0}\right]$ is a easy route in which on conversion is direction with number of reach. In the next pass of route BA, the workpiece is twisted $90^{\circ}$ times in both $\mathrm{CW}$ and $\mathrm{CCW}$ directions. In route $\mathrm{Bc}$, the sample is rotated by $90^{\circ}$ degrees in only one direction in each pass. The sample is spun $180^{\circ}$ times in route C. All paths produce distinct microstructures; the proper route can be chosen based on your needs.

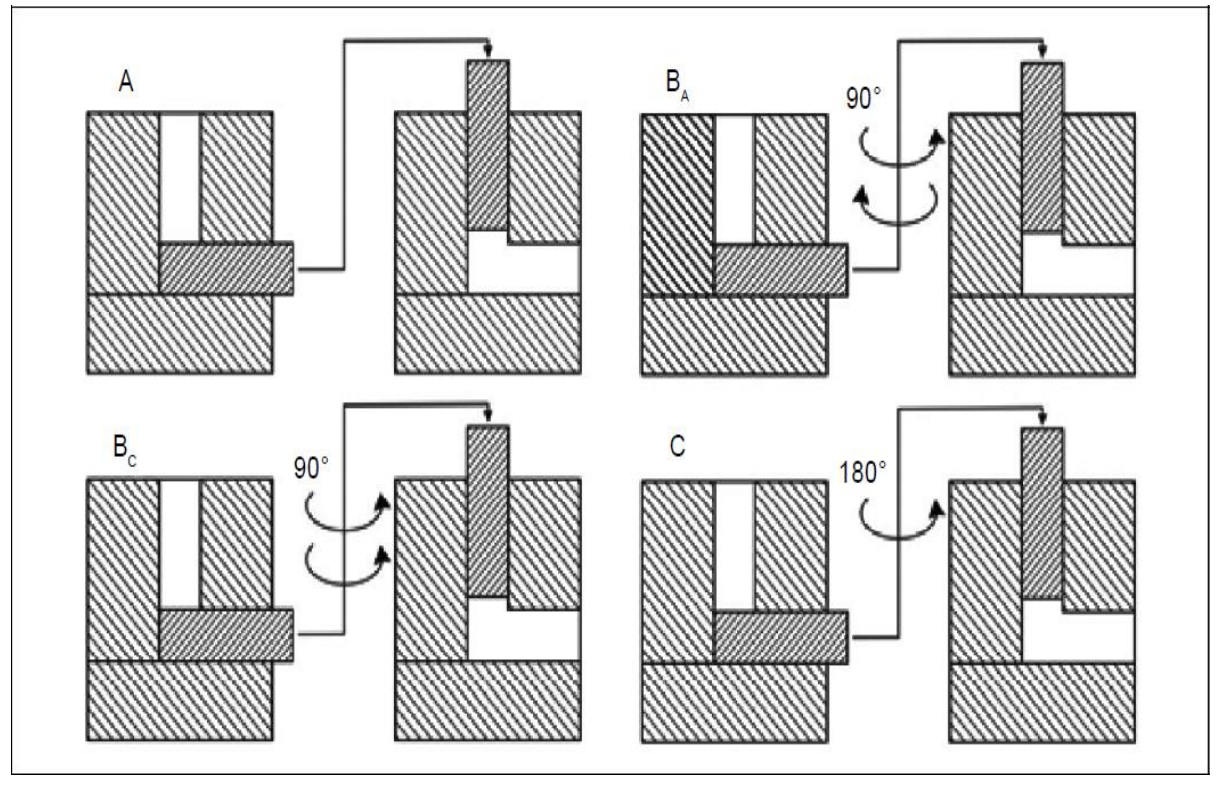

Fig. 2 The four Processing routes for ECAP.

In Fig. 3 for equal channel angular pressing, the corner angle has been optimised. The difference in the graph is due to the fact that the smaller the sample size, the less force is appropriate to force the material and the greater the corner gap development. Taking these considerations into account, as well as the work of other researchers, it is easy to conclude that the corner angle range of $30^{0}-32^{0}$ is optimal for ECAP findings. $0^{0}$ is the ideal corner angle, however its application is limited due to different factors such as coefficient of friction and back pressure. 


\section{International Advanced Research Journal in Science, Engineering and Technology \\ Impact Factor 7.105 Vol. 9, Issue 1, January 2022 \\ DOI: 10.17148/IARJSET.2022.9141 \\ RESULT AND DISCUSSION:}

\section{Die Parameters:}

One of the SPD processes is ECAP, which entails passing a rod-shaped billet through a die with two channels intersecting at a specific angle known as channel angle. The billet is driven through the top channel of the die and out the side channel, after which it must pass through the primary deformation zone, where significant strain is imparted, resulting in grain refinement with no change in overall size. Equal Channel Angular Pressing is certain to be a homogeneous operation, which simply means that the sample has a systematic distribution of stress, because the dimensions of the billet stay stable. As a result, the billet can be processed again for achieving very high strain. There are few elements that may have an impact on its uniformity. Internal and external factors are the two types of factors. constitutional factors are those that are influenced by the material's nature and mechanical qualities. Back pressure,temperature, friction, ram speed, die geometry, rate of loading, and passage routes are examples of external elements that are reliant on die design parameters. Internal variables are largely determined by the workpiece's material and qualities. In the early 1980s, Segal and his team were the first to create ECAP, also known as Equal Channel Angular Extrusion (ECAE). Figure 1 illustrates the materials being processed via the ECAP die with corner angles of (a) 0 , (b) $>0$. Composites are a recent advancement in the development of light-weight, high-strength materials. They have the ability to meet the needs of industry in terms of obtaining the appropriate attributes. A composite that is made by metallurgical process of adding titanium to aluminium. With the help of ECAP, the qualities of these composites can be improved even more. This article looks at the microstructure and mechanical properties of this sample after $0,1,2,3$, and 4 ECAP passes.

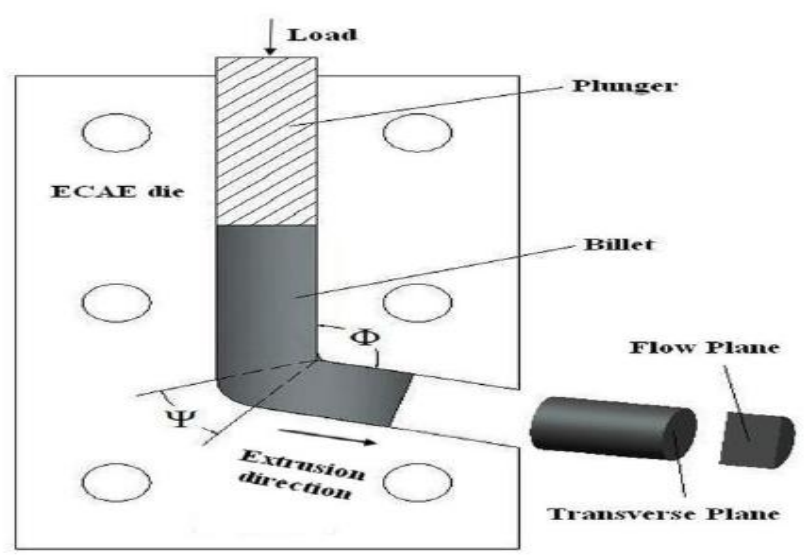

Fig. 3 Schematic diagram showing an ECAP die with processed sample with corner angle $\varphi$ and the channel angle $\varnothing$.

\section{Effect of number of passes on mechanical Properties:}

Guzide et al. [28] use Taguchi and experimental methodologies to optimise the process parameters and improve the hardness of an Al-Zn-Mg alloy. HRTEM and EBSD deconstruction were used after the experiments to identify which sample had the highest toughness and smallest grain size. After analysing all of the data, BC was determined to be the optimal condition for maximal microhardness and smallest grain size, with eight passes and a temperature of $100 \mathrm{C}$ throughout the experiment. Further investigation indicated that the number of passes was proportionate to the hardness, meaning that as the number of passes increased, so did the microhardness of the material. However, increasing the change in process temperature from 120 to $220 \mathrm{C}$ may result in a considerable reduction in specimen hardness. According to Taguchi analysis, For pass number, route taken, and temperature, the influence percentages of various input parameters are 70, 30, and 3.2 percent, respectively. All different parameters, such as pressing speed and friction, have an unpredictable impact on micro-hardness. In article Using six passes and route Bc, Maged et al. [29] investigate the ECAP effect on AA7075-T6 aluminium alloys at room temperature. Improved tensile strength and micro-hardness were carry out during the experiment. Tensile strength and micro-hardness were improved during the experiment. Hardness increased rapidly in the first three passes, from $170 \mathrm{HV}$ to $195 \mathrm{HV}, 210 \mathrm{HV}$, and $215 \mathrm{HV}$ after one Pass, two Pass, and three Pass, respectively. However, this does not rule out the possibility of increasing hardness after three passes; in Figure. 3, a little increase in micro-hardness was observed as the number of passes rose. The sample's final microhardness after six passes is around $228 \mathrm{HV}$. Figure 4 shows Stress-Strain curves for an Al-Zn-Mg alloy before and after the ECAP process with six passes. The first sample had high ductility and poor strength, according to the results. The original sample's ultimate tensile strength (UTS), yield strength (YS), and extension percentage values were $418 \mathrm{MPa}, 299 \mathrm{MPa}$, and 12.5 percent, respectively. The loss of ductility has been observed as the UTS increases. Furthermore, following the first pass of the ECAPed process, The yield strength rises drastically from $303 \mathrm{MPa}$ to $510 \mathrm{MPa}$, a considerable 72.6 percent increase. ECAP continues to pass end ups, steadily increasing in strength. The sample's ultimate tensile and yield strengths after 6 


\section{International Advanced Research Journal in Science, Engineering and Technology \\ Impact Factor 7.105 다. 9, Issue 1, January 2022 \\ DOI: $10.17148 /$ IARJSET.2022.9141}

progress were approximately $653 \mathrm{MPa}$ and $610 \mathrm{MPa}$, respectively. However, as the number of passes increases, the ductility, or elongation ratio, decreases, reaching a low of roughly 6.93 percent. These were the expected results, which were similar to those in reference [44]. Suresh et al. [52] used route A with four ECAP passes to successfully apply ECAP to the Al-Cu-Li alloy AA2195 at $250 \mathrm{C}$. With an increase in Equal Channel Angular Pressing passes, improvements in UTS, micro-hardness, young modulus can be attributed to GB strength, precipitation strength, and dislocation strength, After four passes, the changes in mechanical properties show a significant increase in reduction in elongation. tensile property, and a micro-hardness.

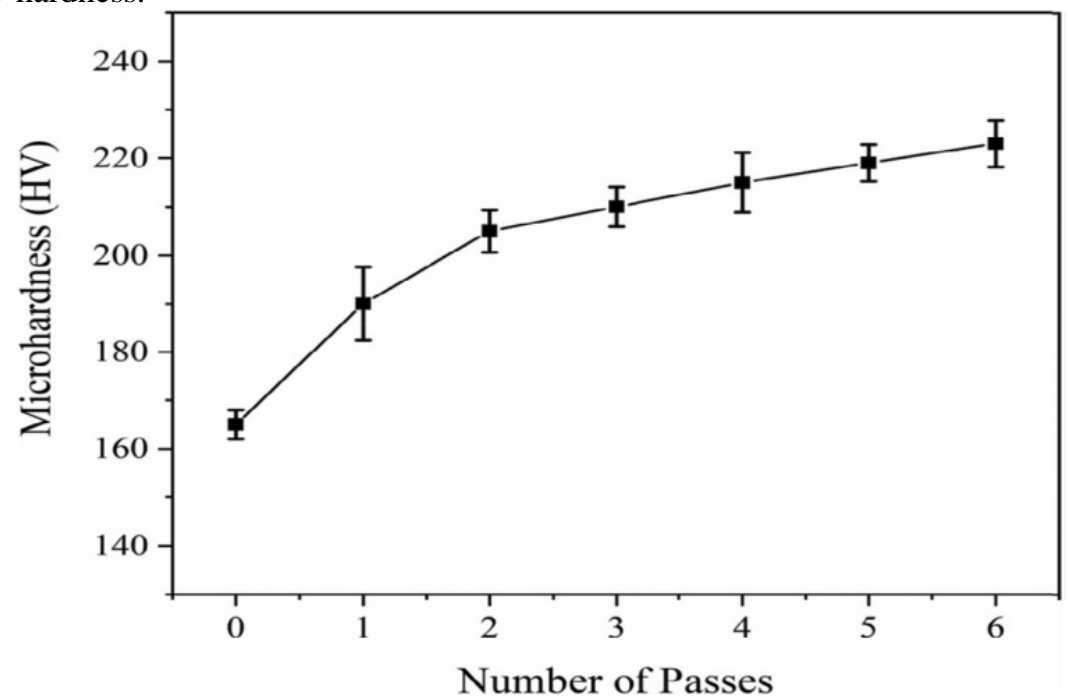

Fig. 4. Effect of Various Number of passes on micro-hardness [29].

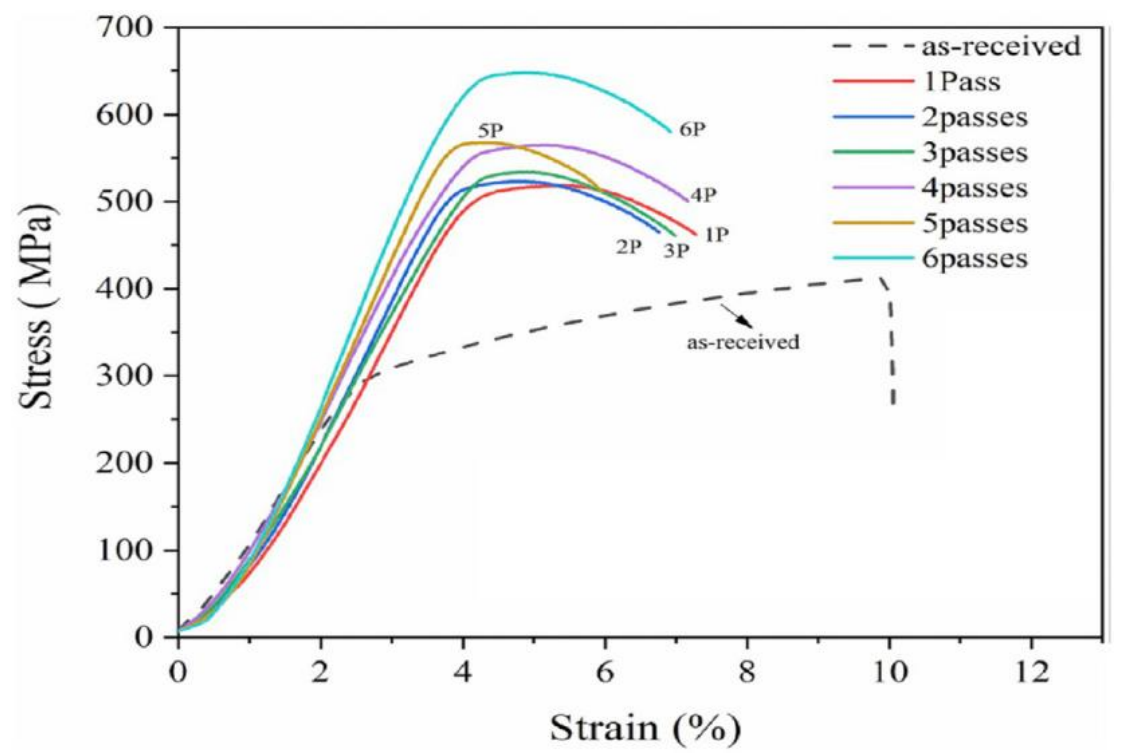

Figure 5. ECAPed specimens with different number of passes (1 to 6) and Stress-Strain graph [29].

The starting hardness was around $1218 \mathrm{MPa}$, but after four passes, it had grown to $1512 \mathrm{MPa}$. The traditional Hall-Petch behaviour of grain size reduction as hardness increases is visible. Figure 5 depicts the effect of ageing on hardness, showing hardness values for the initial sample and the 4 pass sample with and without ageing. The UTS,elongation percentage and YS had initial values of $459 \mathrm{MPa}, 335 \mathrm{MPa}$, and 20 percent, respectively. The initial sample had a lower strength and more elongation, which could be seen. Furthermore, increasing the number of passes enhances the strength properties, and after four passes of ECAP, there was a consistent decrease in elongation. In addition, four passes with ageing result in marginally better strength when compared to four passes without ageing. 


\section{International Advanced Research Journal in Science, Engineering and Technology \\ Impact Factor 7.105 Vol. 9, Issue 1, January 2022 \\ DOI: 10.17148/IARJSET.2022.9141}

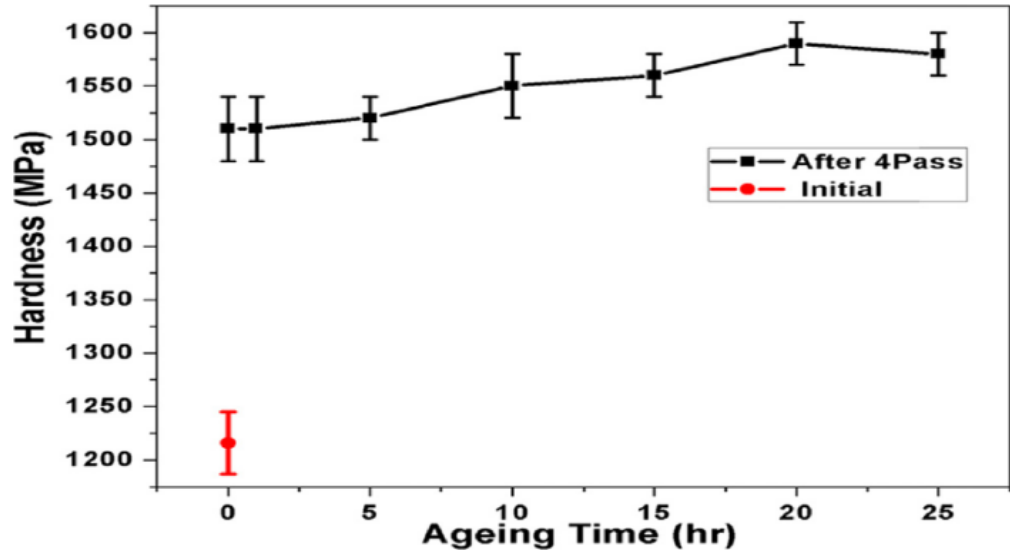

Figure 5. The Four passes ECAPed sample with ageing at $150 \mathrm{C}$ for a different ageing time and micro-hardness of the as received sample and [52].

However, as people get older, they see a decrease in elongation. Kazemi and colleagues Following the first pass, the tensile and yield strengths increased by 152 percent and 48 percent, respectively. Furthermore, as compared to the initial samples, After four passes, the final increment is roughly 238 percent and 83 percent, respectively. The elongation is reduced by around $41 \%$ percent after one pass, similar to Fujinami et al. [52], for a total reduction of around 62 percent.

\section{Influence of the number of passes on microstructure:}

1.1 Guide et al. [42] optimise the ECAP variables to better the mechanical and micro-structural properties of $\mathrm{Al}-\mathrm{Zn}-\mathrm{Mg}$ Alloy using the Taguchi approach. To begin with step of micro-structural investigation, grain deflect was discovered using a deformity effect. Dislocations generally connect and entangle, generating deformity boundary that circulate the quantity into deformity cell sub-grains. Uncertain deformation develops in a broader region than previously, forming deformity centres or entangles. Grain placement, equiaxed grain development and grain size deduction are all good reasons for increasing the number of sub-grains produced by increasing the pass number. Because of SPD, grains are commonly oriented in the extrusion direction following the ECAP process. The "matrix a-Al phase (dark areas)" contains the MgZn2 complex [46-47]. EBSD photos of beginning and after ECAP with eight passes at $110 \mathrm{C}$ following the Bc pathway shown in Figure 6. The initial sample's average grain size after two hours of annealing at $420 \mathrm{C}$ is between 10 and $70 \mathrm{~lm}$. After eight runs of the ECAPed procedure, the average grain size is reduced, as shown in Figure 6. The misorientation angle graph shows that specimens with submicron and nano grain sizes reach the HAGB from the LAGB. It was discovered that LAGB were first created in whole-grains using the SPD approach, and subsequently submicrons/Nano grains were created using the HAGB technique, resulting in an increase in the route effectiveness of the mechanism and number of passes [48]. At room temperature, Maged et al. [42] used a cold ECAP approach to increase the strength of an Al-Mg-Zn alloy. The initial material's TEM micro-structural data are shown in Figure 6. The grain size of the original sample is approximately $2.05 \mathrm{~lm}$, as notice in Figure 6. The original sample's grains are equiaxed and identical to those of Park et al. [49,50]. The TEM micro-structural data show reveal two types of precipitates. The first can be visible at both the grain boundary and interior the grain, with an moderate amount of $55 \mathrm{~nm}$ and a spherical morphology. It refers to SAED and EDX-determined g phases comprising $\mathrm{Mg}, \mathrm{Zn} 2$, and $\mathrm{MgMn} 2$. The second precipitate, which disperses the grain interior, is identified as spherical g' phases measuring 5-10 nm in size. After one pass, the material's average grain size is $415 \mathrm{~nm}$, and the grains are extended. There were also masses of intercrytalline deformity labyrinth, analogous to the ones found by Shaeri et al. [51]. Furthermore, g phase precipitates have an average size of 18 $\mathrm{nm}$, while g' phase precipitates have a moderate amount of $12 \mathrm{~nm}$. Later three passes, the sample's average grain size is less than $210 \mathrm{~nm}$, and the dislocation density falls as the number of shot increase. Furthermore, several elongated grains were discovered, resulting in a moderate particle capacity of roughly $294 \mathrm{~nm}$. Later 3 shots, the amount of g phase precipitate with a moderate size of $38 \mathrm{~nm}$ is decresed. More spherical g' phase precipitates with a moderate size of $10 \mathrm{~nm}$ are present, though. The micro-structural alterations after 6 Equal Channel Angular Pressing passes are illustrated in Figure 6. The continual grain refinement progression shown in Figure 6. resulted in a lot more refined grains than to three passes with an granule size on average roughly $106 \mathrm{~nm}$. Dislocation Convoluted are mutely discovered in few huge grains, and GB is also richer in explanations, resulting in the designation of the new equilibrium grain borders. The g' phase precipitates with a moderate grain amount of roughly $14 \mathrm{~nm}$, as seen in Figure 6. In addition, the Guinier- Preston area was not discovered in the sixth shot, indicating that the Guinier-Preston zone had entirely changed to the g' phase. Sharma et al. [30] investigate the effects of ECAP above the AA2195 Al-Cu-Li alloy. The granule size of the original material is 


\section{International Advanced Research Journal in Science, Engineering and Technology \\ Impact Factor $7.105 \div$ Vol. 9, Issue 1, January 2022 \\ DOI: 10.17148/IARJSET.2022.9141}

on average $58.8 \mathrm{~mm}$, with large grains that have been stretched along the rolling direction and acute angle grain confines, showing substantial disorientation growth in elongated grains. Figure 9 shows the grain reference orientation deviation maps and inverse pole figures produced with EBSD observations of all 4 ECAPed samples. The profile of grain size distribution grows finer as the number of passes enlarge. The average grain sizes following the first, second, third, and fourth ECAP passes are 9 1.4, 5.6 1.2, 3.7 0.9, and $2.80 .7 \mathrm{~mm}$, respectively. It revealed that the microstructure is diverse, coexisting with equiaxed and stretched grains that have been refined. Equiaxed or elongated refined grains emerge after 2 shots. The heterogeneity and particle size diminish as the The proportion of fine grains in the volume fraction enlarges in the third and fourth passes. After the fourth pass, The primary rough grains are gradually being replaced by freshly refined grains. Indicates the presence of strain due to the formation of disorientation in the microstructure after the first and second passes. After the third and fourth passes, disorientation growth is limited, and most grains are relatively strainfree, with few grains having large disorientation growth shown by arrowheads on the GROD maps. Additionally, as the number of passes enlarged, the average disorientation angle rose. After the first, second, third, and fourth passes, the disorientation angles are 21, 29, 33, and 35, respectively. The GBCD of untreated and treated material. The fraction of high angle boundaries (HAGBs) grows as the number of shots increases. The percentage of HAGBs was primarily around 35 percent, but it had climbed to $78 \%$ by the 4 th run of the ECAP method. The fraction of cheap gradient grain boundaries decreases as the number of passes enlarge.

\section{Limitations of ECAP:}

ECAP has certain restrictions in addition to grain refinement capability. $\mathrm{Xu}$ et al. [41] point out some significant drawbacks of the traditional ECAP process. To begin, The ECAP uses a technique known as forever processing, in this method the sample is inserted into the channel and pushed across it, then discharge in addition, the procedure repeated to accomplish major strain. As a result, Equal Channel Angular Pressing can be an effective lab exploration procedure, but because it is nativity intensive, it may be difficult to completely adapt for industrial manufacturing. Second, due to channel length and plunger displacement limitations, The entire length of the workpiece is limited, and there's a crucial aspect ratio to think about. The disadvantage of ECAP is last but not least that one as well as other ends of the billet have surfaces that are uneven as a result of non-identical deformation, resulting in some cutting waste to bring both ends parallel. This research looks at the effects of the ECAP method on the microstructure and mechanical properties of AA. The process results are influenced by the ECAP input process variables. The following is a summary of these: initially with microhardness, the difficulty level rapidly rises with each repetition. The material's micro-hardness and strength grew as the number of passes enlarged. The number of passes has a higher impact on the material's strength than the temperature for processing. The tensile strength and yield strength of the material might have enhanced by added than $75 \%$ and 210 percent, discretely. As the number of shots increases, the grain size of the initial sample shrinks. The ECAP method transformed the crude grain of the basic pattern into extended grains. Furthermore, after four ECAPed passes, All prolonged grains are converted to ultra-fine grains. LAGBs have a larger formation than HAGBs. The moderate grain it's all about the size affected by temperature than by the number of passes. The ECAP technique produces remarkable mechanical properties by forming high-density, ultra-fine grain size, dislocations, and Nano-precipitation.

\section{CONCLUSION:}

We discovered the impact of ECAP on thermal properties of metals, alloys and the mechanical after performing research and examining many research articles. We intend to undertake more tests with varied ECAP method with compare the grain refinement obtained for channel angles of the die.

- As a result, to achieve a higher level of grain refinement not change the pieces size is the optimum channel angle for the die during ECAP $120^{\circ}$.

- To completing experimental tests, for optimal corner angle is $30^{\circ}$, and the much desirable route for operating ECAP on the AA5000 series is passage BC, with four or much passes.

- Latterly conducting a literature review on 5xxx series AA, we can conclude when with changes in variables such as routes, corner angle, channel angle, number of shots, and so on, to expand mechanical decor such as Yield Strength, Hardness, Ultimate tensile strength, and a reduce in percentage extending of alloys.

- The small force and higher corner angle is appropriate to pass the matter and the higher the corner gap creation. - Major study has been done on AA5083 due to its wide range of applications and the chemical percentage of Magnesium.

- Input method variables of ECAPed have an prestige on the outcome subsequently the case. In this investigate consequence of ECAPed method on the mechanical equity of AA has been checked the microstructure properties.

- The particular can be summarised as follows: initiate with microhardness, it gradually increases along each subsequent iteration. The material's microhardness and strength grew with the move up in the number of shots. The impression of the number of shots on the material's durability is greater than that of the processing temperature. 


\section{International Advanced Research Journal in Science, Engineering and Technology \\ Impact Factor $7.105 \div$ Vol. 9, Issue 1, January 2022 \\ DOI: 10.17148/IARJSET.2022.9141}

- The tensile strength and yield strength of the material might have enhanced by $>70$ percent and 200 percent, subsequently. Because the first sample's grain size was so small, shrinks and the number of shots increases.

- The ECAP method transformed the coarse grain of the initially a sample of elongated grains was taken. Furthermore, after four ECAPed passes, all of the stretched cereal become ultra-fine grains. LAGBs have a larger formation than HAGBs. Temperature has a greater impact the number of passes is greater than the average grain size.

- The ECAP technique produces remarkable mechanical properties by forming Nano-precipitation, ultra-fine grain size, and high-density dislocations.

\section{REFERENCES:}

[1] Bagherpour E, Pardis N, Reihanian M, Ebrahimi R. (2018) An overview on severe plastic deformation: research status, techniques classification, microstructure evolution, and applications. The International Journal of Advanced Manufacturing Technology 100(5-8):1647-1694. https://doi.org/10.1007/s00170-018-2652-z.

[2] Langdon TG (2011) Processing by severe plastic deformation: historical developments and current impact. Mater Sci Forum 667-669:9-14. www.scientific.net/MSF.667-669.9

[3] K. Mohan Agarwal, R. K. Tyagi. And A. Dixit, "Theoretical analysis of equal channel angular pressing method for grain refinement of metals and alloy," Meter. Today Proc., vol.25, no.xxxx, pp. 668-673, 2020, doi: https://doi.org/10.1016/j.matpr.2019.08.026.

[4] Shunqi Wang; Wei Liang; Yu Wang; Liping Bian; Kehua Chen (2009). A modified die for equal channel angular pressing., 209(7):3182-3186. https://doi.org/10.1016/j.jmatprotec.2008.07.022

[5] V.M. Segal (1995) Materials processing by simple shear.,Mater Sci Eng A 197(2):157164. https://doi.org/10.1016/0921-5093(95)09705-8.

[6] Terence G. Langdon; Minoru Furukawa; Minoru Nemoto; Zenji Horita (2000). Using equal-channel angular pressing for refining grain size. , 52(4), 30-33. doi:10.1007/s11837-000-0128-7.

[7] K. Mohan Agarwal, R. K. Tyagi, V. K. Chaubey, and A. Dixit, "Comparison of different methods of severe Plastic Deformation for grain refinement," IOP Conf. Mater. Sci. Engg. Vol.691, no 1, 2019, doi: https://doi.org/10.1088/1757-899X/691/1/012074.

[8] K. M. Agarwal, R. K. Tyagi, and A Kapoor, "Deformation and strain analysis for grain refinement of materials processed through ECAP," Mater, Today Proceeding, no. 1, 2019.

[9] D.M. Jafarlou, E. Zalnezhad, A. S. Hamouda, G. Faraji, N. A. Bin Mardi, and M.A. Hassan Mohamed, "Evaluation of the Mechanical Properties of AA 6063 Processed by Severe Plastic Deformation,” Metall. Mater. Trans. A phys. Metall. Mater. Sci., vol. 46, no.5, pp. 2172-2184, 2015, doi: https://doi.org/10.1007/s11661-015-2806-7.

[10] Djavanroodi F, Ebrahimi M (2010) Effect of die parameters and material properties in ECAP with parallel channels. Mater Sci Eng A 527(29-30):7593-7599. https://doi.org/10.1016/j.msea.2010.08.022

[11] P. Thakur, P. Surve, and S. Sanas, "Advancement in Die Design of Equi-Channel Angular Pressing (ECAP) Process: A Review,” Int. J. Sci. Eng. Res., vol.5, no. 12 pp. 93-96, 2014, [Online]. Available:http://www.ijser.org.

[12] Mathieu JP, Suwas S, Eberhardt A, Toth LS, Moll P (2006) A new design for equal channel angular extrusion. J mater Process Technol 173(1):29-33. https://doi.org/10.1016/j.jmatprotec.2005.11.007

[13] P. Ponce-Pena, E. Lopez-Chipres, E. Garcia-Sanchez, M. A. Escobedo-Bretado, B. X. Ochoa-Salazar, and M. A. Gonzalez-Lozano, "Optimized design of an ECAP die using the finite element method for obtaining nanostructured materials,” Adv. Sci. Eng., vol. 2015, doi: https://doi.org/10.1155/2015/702548.

[14] Dayal, Atul; Hans Raj, K.; Sharma, Rahul Swarup (2018). ECAP Die Design for Minimising Corner Gap. Materials Today: Proceedings, 5(1), 1686 1690. doi:10.1016/j.matpr.2017.11.264.

[15] F. Djavanroodi; M. Ebrahimi (2010). Effect of die channel angle, friction and back pressure in the equal channel angular pressing using 3D finite element simulation., 527(4-5):12301235. https://doi.org/10.1016/j.msea.2009.09.052.

[16] Hans J. Roven; Hakon Nesboe; Jens C. Werenskiold; Tanja Seibert (2005). Mechanical properties of aluminium alloys processed by SPD: Comparison of different alloy systems and possible product areas. , 410-411(none), 426429. doi:10.1016/j.msea.2005.08.112.

[17] Veveçka, Aferdita; Cabibbo, Marcello; Langdon, Terence G. (2013). A characterization of microstructure and microhardness on longitudinal planes of an Al-Mg-Si alloy processed by ECAP. Materials Characterization, 84(), 126-133. doi:10.1016/j.matchar.2013.07.016.

[18] Joon-Yeon Chang; Aidang Shan (2003). Microstructure and mechanical properties of AlMgSi alloys after equal channel angular pressing at room temperature. , 347(1-2), 165-170. doi:10.1016/s0921-5093(02)00577-4.

[19] LIU, Man-ping; JIANG, Ting-hui; WANG, Jun; LIU, Qiang; WU, Zhen-jie; YU, Ying-da; SKARET, Pål C.; ROVEN, Hans J. (2014). Aging behavior and mechanical properties of 6013 aluminum alloy processed by severe plastic deformation. Transactions of Nonferrous Metals Society of China, 24(12), 3858-3865. doi:10.1016/S10036326(14)63543-3. 


\section{International Advanced Research Journal in Science, Engineering and Technology \\ Impact Factor $7.105 \div$ Vol. 9, Issue 1, January 2022 \\ DOI: $10.17148 /$ IARJSET.2022.9141}

[20] Zenji Horita; Takayoshi Fujinami; Minoru Nemoto; Terence G. Langdon (2000). Equal-channel angular pressing of commercial aluminum alloys: Grain refinement, thermal stability and tensile properties. , 31(3), 691701. doi:10.1007/s11661-000-0011-8.

[21] Sahai, Ankit; Raj, K. Hans; Gupta, N.K. (2017). Mechanical Behaviour and Surface Profile Analysis of Al6061 alloy Processed by Equal Channel Angular Extrusion. Procedia Engineering, 173(), 956963. doi:10.1016/j.proeng.2016.12.155.

[22] C.S. Chung; J.K. Kim; H.K. Kim; W.J. Kim (2002). Improvement of high-cycle fatigue life in a 6061 Al alloy produced by equal channel angular pressing. , 337(1-2), 39-44. doi:10.1016/s0921-5093(02)00010-2.

[23] Cheng Xu; Minoru Furukawa; Zenji Horita; Terence G. Langdon (2005). The evolution of homogeneity and grain refinement during equal-channel angular pressing: A model for grain refinement in ECAP. , 398(1-2), 6676. doi:10.1016/j.msea.2005.03.083.

[24] P.K. Chaudhury; B. Cherukuri; R. Srinivasan (2005). Scaling up of equal-channel angular pressing and its effect on mechanical properties, microstructure, and hot workability of AA 6061. , 410-411(none), 316318. doi:10.1016/j.msea.2005.08.023.

[25] Si-Young Chang; Ki-Seung Lee; Seung-Hoe Choi; Dong Hyuk Shin (2003). Effect of ECAP on microstructure and mechanical properties of a commercial 6061 Al alloy produced by powder metallurgy. , 354(1-2), 0220. doi:10.1016/s0925-8388(03)00008-2.

[26] G. Majzoobi; J. Nemati; M. K. Pipelzadeh; S. Sulaiman (2016). Characterization of mechanical properties of Al6063 deformed by ECAE. The International Journal of Advanced Manufacturing Technology, 84(1-4), 663672. doi:10.1007/s00170-015-7709-7.

[27] Ehab A. El-Danaf (2011). Mechanical properties, microstructure and texture of single pass equal channel angular pressed 1050, 5083, 6082 and 7010 aluminum alloys with different dies. , 32(7), 38383853. doi:10.1016/j.matdes.2011.03.006

[28] R Raj Mohanl, R Venkatraman, S Kabilan and S Raghuraman. A review on deformation studies of aluminum alloys processed through equal channel angular pressing.

[29] Agarwal, Krishna Mohan; Tyagi, R K; Saxena, Kuldeep K (2020. Deformation analysis of Al Alloy AA2024 through equal channel angular pressing for aircraft structures. Advances in Materials and Processing Technologies, 1-15. doi: 10.1080/2374068X.2020.1834756.

[30] K. M. Agarwal, R. K. Tyagi and A. Kapoor, Deformation and strain analysis for grain refinement of materials processed through equal channel angular pressing, Materials Today: Proceedings, https://doi.org/10.1016/j.matpr.2019.11.072

[31] Y. Iwahashi, J. Wang, Z. Horita, M. Nemoto, T.G. Langdon, Principle of equal channel angular pressing for the processing of ultra-fine grained materials, Scripta Mater. 35 (2) (1996) 143-146.

[32] Hyoung Seop Kim, Min Hong Seo, Sun Ig Hong, Finite element analysis of equal channel angular pressing of strain rate sensitive metals, J. Mater. Process. Technol. 130-131 (2002) 497-503.

[33] A.V. Nagasekhar, Yip Tick-Hon, S. Li, H.P. Seow, Effect of acute tool-angles on equal channel angular extrusion/pressing, Mater. Sci. Eng. 410-411 (2005) 269-272.

[34] S.W. Chung, H. Somekawa, T. Kinoshita, W.J. Kim, K. Higashi, “ The Nonuniform behavior during ECAE process by 3D, FVM simulation" 50 (2004) 1079-1083.

[35] W Hufnagel, Key to Aluminium Alloys, Aluminium Publication, Dusseldorf, Germany, 1999.

[36] T. R. Ramachandran, "Advances in Aluminium Processing and Its Automotive Application,"Workshop Lecture Notes, pp. 28- 32, Indian Institute of Metals, Pune Chapter, 2006.

[37] F. Djavanroodi,B.Omranpour,M.Ebrahimin, M.Sedighi Designing of ECAP parameters based on strain distribution uniformity Progress in Natural Science: Materials International 2012;22(5):452-460.

[38] Ayat Fadhil1, Saad Sami Alkhfaji1,3and Mustafa K. Ismael Design Parameters for Equal-Channel Angular Pressing (ECAP) Via Numerical Approach Journal of Physics: Conference Series 1973 (2021) 012103 https://doi:10.1088/1742-6596/1973/1/012103.

[39] P. Vishnu, R. Raj Mohan, E. Krishna Sangeethaa et al., A review on processing of aluminium and its alloys through Equal Channel Angular Pressing die, Materials Today: Proceedings, https://doi.org/10.1016/j.matpr.2019.04.223.

[40] A. Dayal, A. Sahai, K.H. Raj, R.S. Sharma, Comprehensive study of effect of process parameters in equal channel angular pressing, Indian Joural of Engineering and Materials Science 25(2):113-121.

[41] Kapoor A., Gupta B., Singhal A., Agarwal K.M. (2022), Die Design and Its Parameters for Grain Refinement of AA6XXX Series Through Equal Channel Angular Pressing, https://doi.org/10.1007/978-981-16-5281-3_32.

[42] G.M. Lule Senoz, T.A. Yilmaz, Optimization of Equal Channel Angular Pressing Parameters for Improving the Hardness and Microstructure Properties of Al- Zn-Mg Alloy by Using Taguchi Method, Met. Mater. Int. (2020), https://doi.org/ 10.1007/s12540-020-00730-9.

[43] M. Elhefnawey, G.L. Shuai, Z. Li, M. Nemat-Alla, D.T. Zhang, L. Li, On achieving superior strength for Al-MgZn alloy adopting cold ECAP, Vacuum. (2020), https://doi.org/10.1016/j.vacuum.2020.109191. 


\section{International Advanced Research Journal in Science, Engineering and Technology \\ Impact Factor $7.105 \div$ Vol. 9, Issue 1, January 2022 \\ DOI: 10.17148/IARJSET.2022.9141}

[44] Y. Duan, L. Tang, G. Xu, Y. Deng, Z. Yin, Microstructure and mechanical properties of 7005 aluminum alloy processed by room temperature ECAP and subsequent annealing, J. Alloys Compd. (2016), https://doi.org/10.1016/j.jallcom.2016.01.022.

[45] Z. Horita, T. Fujinami, M. Nemoto, T.G. Langdon, Improvement of mechanical properties for Al alloys using equalchannel angular pressing, in, J. Mater. Process. Technol. (2001), https://doi.org/10.1016/S0924-0136(01)00783-X.

[46] M.H. Shaeri, M.T. Salehi, S.H. Seyyedein, M.R. Abutalebi, J.K. Park, Microstructure and mechanical properties of Al-7075 alloy processed by equal channel angular pressing combined with aging treatment, Mater. Des. (2014), https://doi.org/10.1016/j.matdes.2014.01.008.

[47] M. Chegini, M.H. Shaeri, Effect of equal channel angular pressing on the mechanical and tribological behavior of Al-Zn-Mg-Cu alloy, Mater. Charact. (2018), https://doi.org/10.1016/j.matchar.2018.03.045.

[48] Z. Zhang, J. Wang, Q. Zhang, S. Zhang, Q. Shi, H. Qi, Research on grain refinement mechanism of 6061 aluminum alloy processed by combined SPD Methods of ECAP and MAC, Materials (Basel). (2018), https://doi.org/10.3390/ma11071246.

[49] J.K. Park, A.J. Ardell, Precipitate microstructure of peak-aged 7075 Al, Scr. Metall. (1988), https://doi.org/10.1016/S0036-9748(88)80114-5.

[50] J.K. Park, A.J. Ardell, Microstructures of the commercial $7075 \mathrm{Al}$ alloy in the T651 and T7 tempers, Metall. Trans. A. (1983), https://doi.org/10.1007/BF02662363.

[51] M.H. Shaeri, M. Shaeri, M. Ebrahimi, M.T. Salehi, S.H. Seyyedein, Effect of ECAP temperature on microstructure and mechanical properties of Al-Zn-Mg-Cu alloy, Prog. Nat. Sci. Mater. Int. (2016), https://doi.org/10.1016/j.pnsc.2016.03.003.

[52] M. Suresh, A. Sharma, A.M. More, R. Kalsar, A. Bisht, N. Nayan, S. Suwas, Effect of equal channel angular pressing (ECAP) on the evolution of texture, microstructure and mechanical properties in the Al-Cu-Li alloy AA2195, J. Alloys Compd. (2019), https://doi.org/10.1016/j.jallcom.2019.01.161.

[53] Bhuwan Gupta*, Arshit Kapoor, Abhishek Singhal and Krishna Mohan Agarwal Effect of Die Design parameters on materials processed by Equal Channel Angular Pressing IOP Conf. Series: Materials Science and Engineering 1168 (2021) 012005 https://doi:10.1088/1757-899X/1168/1/012005. 